\title{
Divulgacão e ensino de Astronomia e Física por meio de abordagens informais
}

\author{
Dissemination and teaching of Astronomy and Physics through informal approaches
}

\author{
Edio da Costa Junior ${ }^{*}$, Bruno da Silva Fernandes ${ }^{2}$, Guilherme da Silva Lima ${ }^{2}$, Andreza de Jesus \\ Siqueira $^{1}$, Jéssica Natália Miranda Paiva ${ }^{1}$, Marina Gomes e Santos ${ }^{1}$, João Pedro Tavares ${ }^{1}$, Taynara \\ Vitória de Souza ${ }^{1}$, Thaciara Marcela Ferreira Gomes ${ }^{1}$ \\ ${ }^{1}$ Instituto Federal de Minas Gerais, Campus Ouro Preto, MG, Brasil \\ ${ }^{2}$ Universidade Federal de Ouro Preto, MG, Brasil
}

Recebido em 18 de Fevereiro, 2018. Revisado em 31 de Março, 2018. Aceito em 07 de Abril, 2018.

\begin{abstract}
A Astronomia é uma das mais antigas ciências naturais, tendo sido desenvolvida por diferentes civilizações e com distintos propósitos nos últimos milênios. No Brasil, vários tópicos astronômicos permeiam a educação básica, tanto em nível fundamental quanto médio. Somado a isso, nas últimas décadas vem crescendo o número de pesquisas e o interesse pela divulgação científica e pelo ensino em espaços não-formais de educação. As atividades educacionais e a divulgação científica nesse contexto, se bem exploradas, podem contribuir para a socialização e a popularização de conhecimentos sobre Astronomia. Além disso, podem servir de suporte à formação de professores e alunos. Dessa forma, o debate sobre o tema é importante e deve ser instigado tanto no âmbito não acadêmico quanto no âmbito da formação docente e discente. Frente a isso, um projeto de extensão da Coordenadoria de Física (CODAFIS) do Instituto Federal de Minas Gerais - Campus Ouro Preto (IFMG-OP) foi iniciado em 2011, oferecendo observações e atividades sobre Astronomia para a população local e das cidades vizinhas. Desde então, mais de 7.000 pessoas já participaram das ações, demonstrando o imenso potencial do tema. As discussões sobre Astronomia levam normalmente a discussões sobre Física, quando conceitos e vários outros assuntos podem ser tratados de forma aplicada, fomentando o interesse por esses temas. No entanto, atividades mal elaboradas ou mal desenvolvidas podem gerar reações adversas no público, causando resistência com relação ao assunto. Assim, esse artigo tem como objetivo principal identificar elementos que podem culminar com a não efetividade das atividades de observação. Além disso, busca-se identificar parâmetros que sejam determinantes para o êxito das ações, além de compartilhar conhecimentos empíricos obtidos com o desenvolvimento do projeto e encorajar grupos, acadêmicos ou não, a desenvolverem atividades astronômicas similares em ambientes formais e não-formais de ensino e também em diferentes regiões do país.

Palavras-chave: Divulgação científica, observações astronômicas, ensino de Astronomia, educação em espaços não formais, ensino de Física.
\end{abstract}

\begin{abstract}
Astronomy is one of the oldest natural sciences and have been developed by different civilizations and with different purposes in the last millennia. In Brazil, several astronomical topics are teached in basic education, both at the fundamental and medium levels. In addition, the number of researches and activities about scientific dissemination and teaching in non-formal places is increasing. Educational activities and scientific dissemination in this context, if well done, can contribute to the socialization and popularization of astronomy knowledge. Besides that, they can help to improve the knowledge of teachers and students. In this way, the debate on the subject is important and should be instigated both in the non-academic context and in the scope of teacher and student training. In this way, a practical project of the Physics Department (CODAFIS) of the Federal Institute of Minas Gerais - Campus Ouro Preto (IFMG-OP) was started in 2011, offering observations and activities on Astronomy for the local population and neighboring cities. Since then, more than 7,000 people have attended the actions, which shows the large potential of the theme. Astronomy discussions naturally lead to Physics, when concepts and many other subjects can be treated in an applied way. In general, people are more interested in activities in this context than in traditional teaching environments. However, poorly designed or poorly developed activities can generate adverse reactions in the public, leading to dislike on the subject. Thus, this article's main objective is to identify elements that can culminate with the non-effectiveness of the observation activities. In addition, it seeks to identify parameters that are determinant for the success of the actions, in addition to sharing empirical knowledge obtained with the development of the project and to encourage groups, academic or otherwise, to develop similar astronomical activities in formal and non-formal educational environments and also in different regions of the country.

Keywords: Scientific divulgation, astronomical observations, Astronomy teaching, education in non-formal spaces, Physics
\end{abstract} teaching.

\section{Introdução}

O homem tem se interessado pelos fenômenos espaciais por milênios, o que faz da Astronomia uma das mais antigas dentre as ciências naturais. Existem registros de vários povos e em diferentes épocas sobre auroras, fases da Lua e meteoros (popularmente conhecidos como estrelas cadentes), por exemplo [1] 3]. Esses fenômenos se encarregaram de mexer com o imaginário popular até que suas origens pudessem ser minimamente compreendidas.

*Endereço de correspondência: edio.junior@ifmg.edu.br 
Desde a antiguidade a humanidade aprendeu a usar o céu em seu favor, orientando-se pelas estrelas nas grandes viagens e usando os fenômenos celestes para a marcação de tempo na agricultura, por exemplo [4]. Muito foi aprendido e especulado sobre o universo apenas por meio da observação a olho nu do céu. Se por um lado uma parte considerável das informações da época eram de cunho religioso e místico, além de permeadas por conceitos da Astrologia, por outro houve diversas correntes da filosofia natural que também propuseram modelos para compreender fenômenos astronômicos com base, especialmente, na razão, em especial as academias gregas [1, 2, 4]

Entretanto, um salto gigantesco foi dado pela Astronomia após a invenção do telescópio pelo holandês Hans Lippershey (1570-1619), que construíu o primeiro instrumento em 1608 na Holanda. Galileo Galilei (1569-1642) tomou conhecimento dessa invenção na Itália em 1609 e, no mesmo ano, sem ter visto o aparelho original construído por Lippershey, construiu o seu próprio, com um poder de ampliação de imagens de aproximadamente três vezes [4, 5]. Desde então as pessoas olham para o céu com instrumentos que ampliam consideravelmente suas capacidades visuais.

Os Parâmetros Curriculares Nacionais (PCNs) e suas orientações complementares 6-8] sugerem, desde a década de 1990, que alguns assuntos sobre Astronomia sejam ensinados tanto no Ensino Fundamental quanto no Ensino Médio. No Ensino Fundamental os PCNs delegam os conteúdos principalmente às disciplinas de Ciências e de Geografia, enquanto no Ensino Médio os tópicos ficam sob a responsabilidade da Física.

Mesmo que os estudantes brasileiros tenham contato com a Astronomia em diferentes fases de suas formações, ainda são enormes as dificuldades pelos quais passa o ensino dessa ciência. Dentre os desafios que impactam de forma negativa no processo de ensino-aprendizagem destacam-se: formação deficitária dos docentes ou formação fora da área de ciências 9 15]; falta de conteúdos sobre Astronomia nos cursos de formação inicial [12, 15 17]; professores que lecionam disciplinas diferentes daquelas em que foram formados 12,18,19, difusão de concepções não científicas e falhas conceituais, tanto em alunos quanto em professores [13,20 21], além de erros conceituais históricos trazidos por livros didáticos [13, 14, 22, 24].

No caminho inverso a todos os obstáculos relacionadas ao ensino em ambientes acadêmicos, trabalhos científicos vêm demonstrando cada vez mais o grande potencial motivador que a Astronomia observacional pode gerar sobre as pessoas, tanto em ambientes de educação formal quanto informal 25 28]. Frente a isso, uma equipe do Campus Ouro Preto do Insitituto Federal de Minas Gerais (IFMG-OP) iniciou em 2011 o projeto de extensão "O Céu ao alcance de todos: Um projeto para a popularização e valorização da ciência", com o intuito de socializar conhecimentos e difundir a Astronomia e a Física dentre a comunidade acadêmica e não-acadêmica.

É indiscutível a importância da Astronomia como componente curricular da educação formal, bem como os diversos desafios para seu efetivo ensino nas disciplinas científicas em diferentes níveis. Ressalta-se, portanto, a importância de outros ambientes para a promoção dessa Ciência.

No Brasil, os espaços não formais de ensino têm contribuído há décadas com a formação integral do cidadão, inclusive com a abordagem da Astronomia. Para se ter uma ideia, existem 73 planetários cadastrados junto à Associação Brasileira de Planetários, sejam fixos ou itinerantes, segundo o site da associação. Soma-se a isso os diversos centros e museus de Ciências que possuem alguma seção destinada à Astronomia, além de grupos de estudos sobre o tema que são comuns dentre acadêmicos e entusiastas.

Há que se ressaltar a importância desses tipos de espaços e atividades especialmente porque permitem que qualquer pessoa possa interagir com temáticas relacionadas à Astronomia. Nesse sentido, constituem ações que promovem a popularização e a socialização de conhecimentos astronômicos para grupos amplos e que, em muitos casos, estão afastados dos ambientes acadêmicos tradicionais.

Para além de espaços específicos que propõem a educação astronômica, salientam-se também as diversas propostas não formais promovidas por ações itinerantes, como por exemplo aquelas relatadas nesse trabalho, clubes astronômicos, rodas de conversas e discussões científicas, dentre outras atividades predominantemente itinerantes que não contam com um amplo recurso infraestrutural.

Reconhecidamente, tanto as atividades em ambientes como planetários e museus, quanto as atividades itinerantes de observação ou discussões científicas, possuem suas vantagens se comparadas uma com a outra. Se por um lado os planetários (fixos) podem contemplar uma série de fenômenos astronômicos por meio de simulações, projeções, observações etc., por outro é capaz de atender somente aqueles que têm disponibilidade e recursos para acessá-los. Em contrapartida, as atividades não formais itinerantes são capazes de chegar em locais mais remotos e que podem ser desassistidos de práticas de popularização científica, atingindo assim públicos que nem sempre possuem costume e facilidade de frequentar ambientes destinados às ciências.

Vale salientar, porém, que sejam em ambientes fixos ou itinerantes, as atividades não formais, em geral, propiciam aos cidadãos um novo contato com a Astronomia. Esse contato pode ser considerado novo, pois as atividades possuem características muito distintas daquelas ações e abordagens a que as pessoas costumam ter acesso em instituições formais de ensino. Ainda que haja intencionalidade nas ações daqueles que atuam em atividades não formais, seus objetivos e características são produtos da interação entre os indivíduos envolvidos e não de uma rígida estrutura acadêmica e curricular 29]. Com isso os sujeitos possuem maior liberdade para interagir com os objetos das atividades, podendo correlacionar a Astronomia com seus contextos e experiências de vida, bem como expandir suas relações com esses novos objetos. 
Por constituirem atividades que permitem a flexibilização das ações, é bastante comum que sessões não formais sejam diferentes umas das outras, pois o público pode exercer coerções que determinam os percursos das ações desenvolvidas. Com isso, as atividades não formais de ensino são geralmente mais atrativas quando comparadas com as atividades em ambientes formais de ensino.

$\mathrm{O}$ artigo tem o objetivo principal de analisar e compreender elementos que podem culminar com o insucesso de atividades não formais de Astronomia observacional. Além disso, busca-se socializar os conhecimentos obtidos por meio de atividades extensionistas com outros grupos, acadêmicos ou não. Por fim, almeja-se discutir as abordagens mais eficientes em ações desse tipo e encorajar a criação de grupos similares em diferentes regiões e contextos.

\section{Metodologia}

Já foram testadas e aplicadas várias metodologias diferentes, sempre com o intuito de motivar e despertar o interesse do público, além de potencializar a socialização de conhecimentos e as interações entre os participantes e os membros da equipe.

Atualmente, são oferecidas basicamente observações astronômicas com descrições detalhadas dos objetos observados e, concomitantemente, conversa científica com os participantes sobre Astronomia e Física, onde curiosidades e dúvidas podem ser sanadas. Esse modelo de intervenção é fruto da experiência adquirida pela equipe ao longo dos anos.

Na seção de resultados serão apresentadas ações e abordagens que devem ser evitadas nesse tipo de atividade, bem como serão discutidos os motivos pelos quais não foram bem sucedidas, acabando por ser abandonadas.

O telescópio utilizado é do tipo Smicht-Cassegraniano de montagem equatorial e de distância focal igual a 2032 mm. É um aparelho de grande razão focal (f10), ideal para a observação de objetos pouco iluminados, como aglomerados e nebulosas. Dispõe de um conjunto de filtros e de lentes oculares com distâncias focais que variam de $6,4 \mathrm{~mm}$ a $40 \mathrm{~mm}$. Além do telescópio, que certamente é a maior atração do projeto, também há uma luneta que eventualmente é usada.

Com o intuito de atender um grande número de pessoas com diferentes perfis sociais, econômicos e de escolaridade, o projeto é itinerante e percorre diversos bairros e distritos do município de Ouro Preto e de cidades vizinhas. As observações e atividades acontecem nos mais diversos espaços, dentre eles: praças, quadras, escolas, pátios de igrejas, largos, feiras gastronômicas, comunidades rurais, centros comunitários etc. Pelo caráter itinerante, o público é bastante variado, inclusive em uma mesma atividade. Em ações mais amplas, como aquelas que acontecem em praças, por exemplo, é comum que o público seja praticamente renovado a cada 20 ou 30 minutos.

Durante as observações o telescópio é disponibilizado à comunidade em geral. Buscam-se locais de fácil acesso ao público e todas as ações são acompanhadas por membros da equipe, que fazem a montagem, regulagem e operação dos equipamentos, além de atendimento ao público.

A divulgação ocorre através de cartazes afixados no IFMG-OP e próximo aos locais das atividades. Há também o auxílio do setor de comunicação social do campus para a divulgação no site institucional e em rádios, jornais e sites da cidade e da região. Além disso, foi criada uma comunidade no Facebook chamada "Astronomia IFMG", que pode ser diretamente acessada por meio do link https://www.facebook.com/astronomiaifmgop. Nessa comunidade são divulgados os locais e datas das observações, além de notícias e curiosidades gerais sobre Astronomia, Astronáutica e missões espaciais.

\section{Resultados e Discussões}

As intervenções, quando bem planejadas e executadas, têm se mostrado incisivas ao despertar a atenção das pessoas para a ciência. Muitos diretores de escolas da região vêm solicitando observações em suas instituições. Da mesma forma, moradores de bairros e distritos de Ouro Preto e de cidades vizinhas têm procurado frequentemente a equipe para agendar ações em suas comunidades.

Como um resultado secundário, o curso de Licenciatura em Física do IFMG/OP recebeu uma publicidade extra, uma vez que várias pessoas se interessaram pelo assunto. Em conversas com os ingressantes de diferentes turmas do curso, muitos afirmaram que o conheceram quando participaram de observações em suas vizinhanças.

No entanto, apesar do grande interesse que as ações costumam despertar, há que ser ressaltada a grande fragilidade que uma considerável parte da população apresenta com relação à Astronomia, o que evidencia as lacunas e falhas associadas ao ensino dessa ciência. É bastante comum que pessoas do público tenham noções errôneas de escalas de tempo e distâncias astronômicas, ou que não saibam distinguir planetas e satélites naturais, ou planetas e estrelas, por exemplo, que são conhecimentos básicos.

Além disso, inclusive naqueles que têm um bom nível de escolaridade, concepções alternativas são comumente detectadas. Dentre elas, a que mais se destaca é a confusão que frequentemente é feita entre fases da Lua e eclipses lunares. É bastante comum que pessoas associem as fases do satélite à projeção de sombras causadas pela Terra. Outra concepção muito recorrente diz respeito à associação das estações do ano às regiões da órbita terrestre próximas ao periélio e ao afélid 11 relacionando inverno e verão a diferentes distâncias entre a Terra e o Sol. Ideias que remetem a um modelo geocêntrico, com a Terra supostamente no centro do universo, costumam

\footnotetext{
${ }^{1}$ Como as órbitas dos planetas são elípticas, há um ponto de máxima aproximação e um ponto de máximo afastamente entre o planeta e o Sol. Esses pontos são chamados, respectivamente, de periélio e de afélio. Entretanto, a excentricidade das órbitas dos planetas é muito baixa, sendo muito próximas a órbitas circunferenciais.
} 
também aparecer durante as observações. Por fim, é usual que sejam usados pelo público concepções que remetam ao modelo de Terra plana na tentativa de explicar a localização da Terra no universo ou a posição relativa da Lua quando é observada no céu, mesmo que essas pessoas acreditem no modelo de Terra aproximadamente esférica.

A Figura 1 apresenta uma sequência de fotos feitas em Ouro Preto e região, demonstrando a variabilidade de público e de contextos em que as observações acontecem. Em cada quadro da figura é mostrado: A) adolescentes em observação acontecida em Santo Antônio do Salto, comunidade rural que fica a aproximadamente $29 \mathrm{~km}$ de Ouro Preto, em abril de 2013; B) adultos observando sob a orientação de monitor do projeto em janeiro de 2014 na Praça Tiradentes, principal cartão postal de Ouro Preto; C) adultos e adolescentes em atividade acontecida na quadra da Escola Estadual de Ouro Preto, em maio de 2012; D) Atividade com crianças do Ensino Fundamental na Escola Estadual Marília de Dirceu, em Ouro Preto, em outubro de 2012; E) crianças e adolescentes em atividade realizada em Amarantina, comunidade rural a cerca de $31 \mathrm{~km}$ de Ouro Preto, em dezembro de 2012; F) adultos em observação realizada em Mariana, cidade distante aproximadamente $15 \mathrm{~km}$ de Ouro Preto, em julho de 2015; G) adultos e idosos observando em Amarantina, em março de 2016 e H) criança observando com o auxílio do pai no campus do IFMG-OP, em abril de 2016.
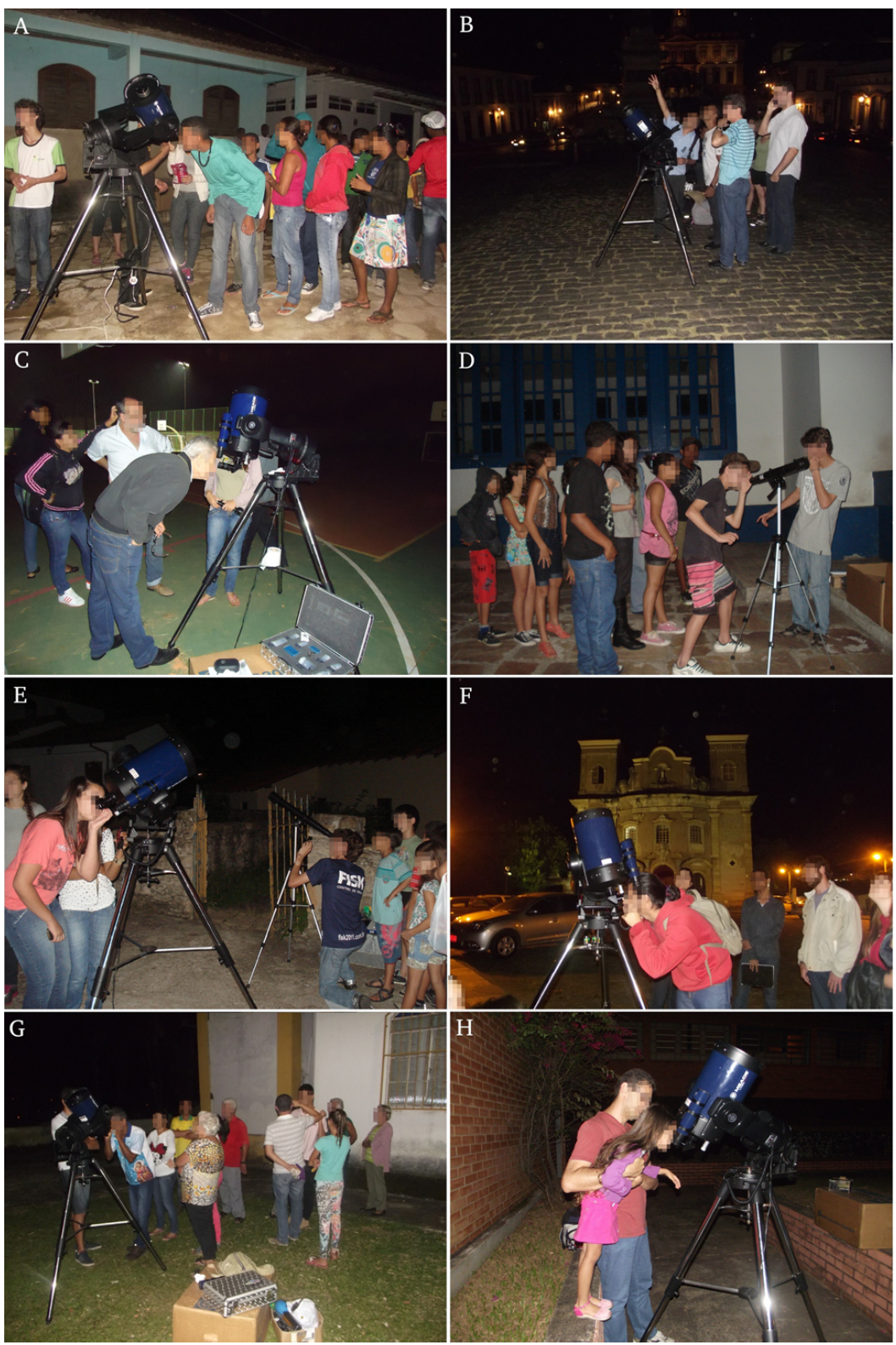

Figura 1: Fotos de observações realizadas em: A) Santo Antônio do Salto, distrito de Ouro Preto-MG; B) Praça Tiradentes, Ouro Preto; C) Escola Estadual de Ouro Preto; D) Escola Estadual Marília de Dirceu, Ouro Preto; E) Amarantina, distrito de Ouro Preto; F) Mariana-MG; G) Amarantina e H) Campus do IFMG-OP. 
Na sequência serão apresentadas e discutidas práticas que não funcionam bem com um público majoritariamente leigo em Astronomia, bem como aquelas que são efetivas em abordagens desse tipo.

\subsection{Práticas Ineficientes em um Contexto de Atividades Extensionistas}

A estratégia adotata inicialmente pela equipe do projeto incluia palestras sobre Astronomia antes das observações. No entanto, a experiência mostrou que, para um público leigo e variável de um projeto itinerante, essa não é a melhor abordagem. Rapidamente grande parte dos participantes perde o interesse e acaba se dispersando. Em conversas com algumas pessoas que participaram, foi relatado que a desmotivação é causada pelo fato das palestras se assemelharem a aulas tradicionais. Assim, a prática foi substituída po discussões científicas durante as observações, o que gerou resultados muito melhores.

Por outro lado, se o público for composto apenas por pessoas altamente interessadas no assunto, as palestras podem funcionar perfeitamente, como foi o caso de algumas abordagens específicas realizadas. Desse modo, essa estratégia só é recomendada caso haja uma seleção prévia dos participantes.

Outra tática que não apresentou resultados satisfatórios foi a apresentação de séries sobre Astronomia. Por tratar de temas específicos por meio de abordagens de cunho mais acadêmico, apenas um pequeno percentual dos participantes costuma se interessar e a prática também foi abandonada. Novamente, deve ser destacado que, para um público com alto interesse em Astronomia a estratégia funciona bem. Caso contrário, deve ser evitada.

Algumas sugestões de séries para incluir em atividades com públicos específicos são: 1) "ABC da Astronomia", série básica de 30 episódios curtos, com cerca de 5 minutos cada um, produzida pela TV Escola, apresentando alguns dos principais conceitos astronômicos. O grande diferencial da série é apresentar o ponto de vista do hemisfério sul; 2) "Espaçonave Terra", série produzida pela TV francesa cuja proposta é acompanhar a trajetória da Terra durante uma translação, ao longo das 52 semanas do ano; 3) "Cosmos", clássica série de TV realizada por Carl Sagan e sua esposa, Ann Druyan, ainda na década de 1980 e 4) "O Universo", série científica de TV produzida pelo canal americano History Channel no formato de documentário.

Com relação às observações propriamente ditas, os planetas Mercúrid ${ }^{2}$ Vênus ${ }^{3}$ e Marte não funcionaram

${ }^{2} \mathrm{O}$ trânsito de Mercúrio, caracterizado pela passagem do planeta entre a Terra e o Sol, constitui algo interessante a se observar. Entretanto, tal passagem somente pode ser visualizada em observações diurnas.

${ }^{3}$ Vênus apresenta fases como a Lua, que são resultantes de sua posição relativa ao Sol e à Terra. Além disso, é possível observar alterações aparentes em seu tamanho devido à aproximação e ao afastamento do planeta em relação à Terra. Entretanto, a mudança muito bem. Isso ocorreu porque o telescópio usado não é apropriado para visualizar esses planetas em detalhes. Assim, a impossibilidade de identificar detalhes e características distintas daquelas vistas a olho nu acaba por desinteressar e desmotivar o público.

Se a observação acontecer com um telescópio adequado, com maior abertura angular e poder de ampliação de imagens, os planetas indicados podem se tornar bastante atrativos. Caso contrário, a estratégia mais indicada é que eles sejam incluídos apenas em observações que envolvam corpos mais interessantes aos olhos do público em geral, mas não é aconselhável que uma observação seja composta por apenas um ou mais deles.

Quanto aos locais das atividades, certifique-se de que o lugar selecionado permitirá uma boa visão do céu. Prédios, muros, postes, fios e árvores, por exemplo, podem facilmente impossibilitar a observação de objetos que estejam baixos, próximos ao horizonte. A impossibilidade de se observar imposta por obstáculos físicos é algo que causa grande decepção no público, além de demostrar despreparo por parte dos executores.

Para uma observação com mais qualidade deve-se escolher, obviamente, locais escuros, longe da contaminação luminosa dos centros urbanos. Entretanto, esses lugares costumam ser afastados e de difícil acesso ao público. Assim, infelizmente, em abordagens extensionistas tais locais não são a melhor escolha, já que o número de participantes é, em geral, drasticamente reduzido nessas situações. Assim, no caso de um público previamente selecionado e de reconhecido interesse no assunto, selecione locais escuros, mesmo que sejam de difícil acesso. Entretanto, para o público geral, evite-os. Um pouco de iluminação em uma ação extensionista não é tão desastroso quanto uma atividade esvaziada.

Por outro lado, locais com grandes aglomerações também devem ser evitados. É bastante tentador agendar observações onde acontecem festas ou comemorações populares, por exemplo, já que o público nesses casos é garantido. Entretanto, é difícil conduzir uma observação em meio a tanta gente, pois há muitos objetos que devem ser transportados e estarem sempre à vista, como por exemplo a própria caixa ou estojo do telescópio, caixas de lentes, lanternas, câmera para registro das atividades, caderno ou equivalente para controle de presença dos participantes, caixas de pilhas ou baterias, extensões e conectores elétricos (caso se trabalhe com o telescópio ligado diretamente à rede elétrica), dentre outros.

Assim, montar um telescópio nesse tipo de ambiente, além de trazer transtornos para a equipe, acaba oferecendo dificuldades à movimentação de pessoas que estão no local única e exclusivamente por causa da comemoração. Essas pessoas podem inclusive se tornarem avessas à atividade. No fim das contas, a ação pode, ao invés de aproximar a Astronomia do público, acabar criando alguma barreira e repulsa nas pessoas.

de fase causada por mudanças de iluminação, bem como o tamanho aparente variável, requerem observações em várias noites diferentes e destoam de atividades de divulgação propostas em intervenções itinerantes. 
Além das desvantagens que foram apresentadas com relação a uma atividade em meio a uma festa popular, talvez a maior delas diga respeito à grande quantidade de pessoas alcoolizadas em tais situações. Pode ser bastante desagradável aos responsáveis e aos participantes, em especial aos pais que acompanham seus filhos, terem que lidar com uma situação constrangedora ou tensa causada por alguém embriagado. Além disso, a combinação entre multidão e álcool pode ser perigosa para o equipamento, uma vez que trombadas e eventuais quedas podem facilmente acontecer. Assim, a sugestão é que não se proponha observações em tais situações.

Finalmente, há que se ter uma especial atenção com o acesso da equipe e dos equipamentos aos locais das atividades. É comum que observações aconteçam onde não é possível chegar de carro até o ponto de montagem do telescópio, como é o caso de escolas e parques, por exemplo. Nesses locais a equipe deverá carregar os equipamentos a pé. Além disso, em outras ocasiões é possível que o estacionamento seja proibido na região da ação, o que obriga também a equipe a carregar os equipamentos. Em situações desse tipo, desconhecer o acesso ao lugar da observação pode gerar atrasos. E acredite, atrasos causam uma péssima impressão sobre a equipe e sobre a própria ação. Assim, se forem marcadas atividades onde os membros da equipe não saibam exatamente como ter acesso, procure visitar o local antes para descobrir, ou então entre em contato com pessoas que conheçam a região para obter detalhes de acesso e evitar atrasos desnecessários.

\subsection{Práticas Eficientes em um Contexto de Atividades Extensionistas}

A experiência acumulada ao longo dos quase sete anos de execução do projeto e mais de sete mil pessoas atendidas mostrou que, no contexto em que as atividades acontecem, a abordagem mais adequada é aquela em que são oferecidas observações em conjunto com uma discussão científica entre a equipe responsável e o público. Nessas conversas devem ser apresentadas as principais características e também curiosidades sobre o objeto ou o conjunto de objetos observados. Esse tipo de interação cria um ambiente agradável e descontraído, favorecendo a interação e desinibindo as pessoas.

Não raras foram as vezes em que as discussões sobre Astronomia e ciência de uma forma geral se estenderam por horas. Tais interações ao redor do telescópio acontecem comumente, motivadas por curiosidades e interesse do próprio público. Assim, a equipe deve estar bem preparada e possuir conhecimentos consideráveis, para que as expectativas sejam sempre supridas.

As discussões astronômicas levam frequentemente a discussões sobre Física, que abordam qualitativamente conceitos como massa, pressão, densidade, velocidade, temperatura, leis de consevação, ondas eletromagnéticas, dentre vários outros, sem o formalismo característico de uma aula, por exemplo. Além disso, é comum perceber a curiosidade e o interesse aguçado de alguns participantes com relação a temas mais avançados, como por exemplo energia e matéria escuras, buracos negros, ondas gravitacionais, buracos de minhoca, fusão e fissão nucleares, quasares, pulsares, dentre outros.

Com relação ao que observar em uma atividade extensionista destinada a leigos, sem nenhuma dúvida, a Lua é a principal atração. O motivo desse protagonismo é simples: por ser o astro mais próximo à Terra, é possível observá-la com uma grande riqueza de detalhes com relação a crateras, relevo, sombras e cores. Dessa forma, sua observação agrada tanto os mais interessados quanto os menos envolvidos. Assim, incluir a Lua nas observações é uma boa estratégia para motivar o público. É bastante comum ouvir exclamações do tipo "Uau, a Lua é cheia de buracos!" ou então "Nossa, como é linda!", principalmente vindos de crianças e idosos. Frente a isso, atualmente a equipe do projeto somente agenda observações em datas e horários que seja possível observar o satélite natural e recomenda fortemente que essa técnica seja empregada em atividades similares.

Na sequência, os planetas Saturno e Júpiter se mostram como grandes motivadores. Saturno chama muito a atenção, pois se diferencia dos outros planetas pelo seu sistema de anéis que pode ser perfeitamente visível mesmo com telescópios simples. Além disso, com aparelhos de pequeno porte o seu maior satélite natural, Titâ ${ }^{4}$ pode ser visualizado. Da mesma forma, Júpiter tem se mostrado um grande estímulo, pois até mesmo com lunetas é possível ver seus quatro maiores satélites naturais, as chamadas Luas Galileanas5 além de manchas e cores do planeta. As Luas Galileanas possuem uma grande importância histórica, já que foi a partir das observações feitas por Galileo Galilei que o modelo heliocêntrico foi de fato confirmado. É aconselhável que essa questão seja explorada durante as observações, levando os participantes a refletirem sobre a grande mudança de perspectiva pela qual passou todo o planeta após a queda da concepção geocêntrica de universo.

A observação de nebulosas e aglomerados de estrelas também funciona muito bem. Apontar o telescópio para uma região aparentemente escura do céu e desvendar muitos objetos invisíveis a olho nu tem desempenhado um papel motivador considerável. Além disso, um observador mais atento pode até perceber pequenos detalhes, como nuvens de gás e poeira e também a coloração das estrelas.

Especificamente, com relação às estrelas, há que se ter um cuidado especial. Algumas pessoas podem facilmente se sentir desmotivadas por verem um "pontinho brilhante" (expressão que aparece recorrentemente dentre o público) através do telescópio, não muito diferente do "pontinho brilhante" que pode ser visto a olho nu. Entretanto, situações assim podem ser chaves para que

\footnotetext{
${ }^{4}$ Titã é o segundo maior satélite natural do Sistema Solar e o único que possui atmosfera densa.

${ }^{5}$ Os satélites são chamados de Europa, Io Calisto e Ganimedes, que é o maior satélite natural de todo o Sistema Solar.
} 
se discuta aspectos relacionados às grandes distâncias astronômicas, diferentes tipos de telescópios, propagação de ondas eletromagnéticas, dentre outros aspectos físicos. Ainda que alguns possam continuar desmotivados, a maior parte gosta e se interessa pela discussão levantada.

É extremamente importante que se saiba previamente o que será possível observar no horário previsto para a atividade, além de deixar isso bastante claro ao público. Recomenda-se o uso de softwares como o Stellarium ou o Celestia, por exemplo, que funcionam como planetários virtuais e são bastante úteis para esse fim. Saber bem o horário em que a Lua ou algum planeta "nasce" ou "se põe" ajuda tanto na elaboração quanto na execução da observação. Além disso, são atitudes importantes para conquistar a confiança do público e para deixar claro a capacidade técnica e científica da equipe responsável

No entanto, mesmo se o roteiro da observação for cuidadosamente planejado, uma má divulgação pode comprometer a atividade. Dessa forma, é crucial que o evento seja amplamente divulgado. E nesse quesito o Facebook tem se mostrado um grande aliado. Os meios tradicionais como sites, rádios e cartazes não devem ser abandonados, já que, principalmente, as pessoas mais idosas ou sem acesso contínuo à internet são alcançadas por eles. Entretanto, uma parte significativa da população tem uma conta na rede social e sua abrangência é gigantesca. Para quantificar minimamente, atividades realizadas nos mesmos lugares antes e depois da utilização da rede social na divulgação costumam contar com um número de participantes até quatro vezes maior. Assim, é altamente recomendável que se crie um perfil ou uma comunidade específica para a divulgação das atividades e de notícias sobre Astronomia. Além disso, a atualização periódica é imprescindível, já que a impressão causada por uma página desatualizada é negativa.

É interessante também que os responsáveis tenham em mãos um laptop, um tablet ou pelo menos um smartphone durante as observações. Mesmo se não houver acesso à internet pode-se usar imagens ou vídeos previamente obtidos, reais ou ilustrativos, além dos planetários virtuais para mostrar detalhes de objetos que não poderiam ser visualizados somente como telescópio. Isso é capaz de cativar e manter o público interessado, mesmo se eventualmente houver períodos nublados durante a atividade. Essa prática ainda pode ser útil para que objetos não visíveis no horário da atividade possam ser explorados e discutidos com os participantes, caso haja interesse.

Além disso, é altamente aconselhável o uso de um apontador laser durante as observações, o que facilita bastante para mostrar estrelas ou pontos específicos, evitando assim que alguém observe algum corpo pelo telescópio e ache que está viasualisando outra coisa quando olha diretamente para o céu noturno. Em especial, o apontador é muito importante para fazer distinção entre planetas e estrelas.

Por fim, é importante que a equipe realize um registro de público. A forma mais simples e tradicional de se fazer isso é por meio de um caderno de assinaturas. De posse desses dados, é possível entender claramente os locais e contextos em que as pessoas mais se interessam pelas atividades, além de possibilitar traçar um perfil dos objetos que mais chamam a atenção do público e passar a incluí-los mais frequentemente nas observações.

\section{Considerações Finais e Conclusão}

Buscou-se aqui discutir e compreender os elementos que podem decretar o insucesso de ações de divulgação científica e socialização de conhecimentos por meio de intervenções não formais de educação, bem como compartilhar resultados empíricos adquiridos acerca do uso da Astronomia em tal contexto.

Conforme discutido, há práticas que não são efetivas se utilizadas com um público leigo, mas podem funcionar perfeitamente bem se o público for constituído por pessoas com conhecimentos básicos e interesse sobre o tema. Tais intervenções incluem palestras, apresentação de séries sobre Astronomia, observação de objetos que se apresentem de forma parecida quando observados a olho nu e com o telescópio e atividades em locais de difícil acesso. Cabe aos responsáveis selecionar e mesclar ações de forma a atingir os objetivos e metas estipulados.

As principais práticas que se mostraram eficientes em um contexto de atividades itinerantes, independentemente da familiaridade dos participantes com a Astronomia são: discussões científicas com o público paralelamente às observações e observação de objetos que o telescópio revele detalhes invisíveis a olho nu como a Lua, Júpiter, Saturno, aglomerados e nebulosas, por exemplo. Além disso, as atividades devem ser bem planejadas, divulgadas e executadas. A equipe responsável deve saber com precisão o que e a partir de que horário é possível observar cada objeto proposto. Além disso, conhecer bem o público e sua familiaridade com tópicos astronômicos é primordial para que as ações contemplem as expectativas dos participantes.

Ficou bastante evidente que o ensino de Astronomia apresenta falhas por uma série de motivos já discutidos ao longo do texto. É comum que as pessoas não tenham conceitos e conhecimentos básicos sobre o tema. Isso foi percebido tanto nos participantes da região quanto em turistas de diferentes partes, que frequentemente participam das atividades, em especial daquelas realizadas no centro histórico de Ouro Preto.

O grande número de pessoas atendidas e a considerável receptividade das ações em Ouro Preto e região demonstram o potencial motivador exercido pela Astronomia Observacional. Somado a tudo isso, ainda há as dificuldades enfrentadas pela educação formal com relação ao ensino de Astronomia. Assim, os autores encorajam a criação de projetos e ações semelhantes em diferentes regiões e contextos. Astrônomos amadores e entusiastas podem colaborar sobremaneira para a criação e consolidação dos grupos, garantindo a socialização e a divulgação de conhecimentos em suas comunidades locais. 


\section{Agradecimentos}

Os autores agradecem Ana Carolina de Lima Matos, pelas valiosas contribuições para a realização desse trabalho.

\section{Referências}

[1] S. I. Akasofu e S. Chapman, Solar Terrestrial Physics (Oxford University Press, Oxford, 1972).

[2] M. G. Kivelson e C. T. Russell, Introduction to Space Physics (Cambridge University Press, Cambridge, 1995).

[3] E. Costa Junior, F. J. R. Simões Junior, F. R. Cardoso e M. V. Alves, Revista Brasileira de Ensino de Física, 33, 4, (2011).

[4] K. S. Oliveira Filho e M. F. Saraiva, Astronomia e Astrofísica (Editora da Universidade Federal do Rio Grande do Sul, Porto Alegre, 2000).

[5] A. S. T. Pires, Evolução das Ideias da Física (Livraria da Física, São Paulo, 2011), $2^{\mathrm{a}}$ ed.

[6] Brasil, Parâmetros curriculares nacionais: introdução aos parâmetros curriculares nacionais (MEC/SEF, Brasília, 1997).

[7] Brasil, Parâmetros Curriculares Nacionais (Ensino Médio) (MEC, Brasília, 2000).

[8] Brasil, PCN+ Ensino Médio: orientações educacionais complementares aos Parâmetros Curriculares Nacionais. Ciências da Natureza, Matemática e suas Tecnologias. (MEC, Brasília, 2002).

[9] S. G. Barros, Enseñanza de lãs Ciências, 15, 2 (1997).

[10] P. S. Bretones e M. Compiani, Boletim da Sociedade Astronômica Brasileira, 20, 3 (2001).

[11] D. Delizoicov, Ensino de ciências: fundamentos e métodos, (Cortez, São Paulo, 2002).

[12] R. Langui, Um Estudo Exploratório Para a Inserção da Astronomia na Formação de Professores dos Anos Iniciais do Ensino Fundamental. Dissertação de Mestrado. UNESP, Bauru (2004).

[13] R. Langui e R. Nardi, Revista Latino-Americana de Educacion em Astronomia - RELEA, 2, 75 (2005).

[14] R. Langui e R. Nardi, Caderno Brasileiro de Ensino de Física, 24, 87 (2007).

[15] R. Langui, Astronomia nos anos iniciais do ensino fundamental: repensando a formação de professores. Tese de Doutorado, UNESP, São Paulo (2010).

[16] M. F. O. Saraiva, A. M. Muller e E. A. Veit, in Atas do II Simpósio Nacional de Ensino de Astronomia (Instituto de Física, São Paulo, 2012).

[17] W. Cerqueira Júnior, R. S. Almeida, R. S. Conceição e G. Dutra, Revista Latino-Americana de Educación em Astronomía - RELEA, 20, 115 (2015).

[18] M. E. C. C. Lima e E. Maués, Revista Ensaio, 8, 20 (2006).

[19] C. Leite, Y. Hosoume, Revista Latino-Americana de Educación em Astronomía - RELEA, 4, 47 (2007).

[20] J. Baxter, International Journal of Science Education, 11, 47 (1989)

[21] J. M. Barrabin, Enseñanza de las Ciências, 13, 502 (1995).

[22] N. L. Pretto, A ciência dos livros didáticos, (UNICAMP, Campinas, 1985)

[23] J. B. G. Canalle e I. A. G. Oliveira, Cad.Cat.Ens.Fis., 11, 2 (1994)
[24] D. Puzzo, Um estudo das concepções alternativas presentes em professores de $5^{\mathrm{a}}$ serie do ensino fundamental sobre as fases da lua e eclipses. Dissertação de Mestrado. Universidade Estadual de Londrina (2005).

[25] D. F. C. Jacobucci, Em Extensão, 7, 55 (2008).

[26] A. A. Mees, Astronomia: motivação para o ensino de Física na $8^{\mathrm{a}}$ série. Dissertação de Mestrado. Universidade Federal do Rio Grande do Sul (2004).

[27] C. L de Carvalho, M. H. R. Zanitti, B. L. Felicidade, A. D. T. Gomes, E. W. Dias e F. O. Coelho, Revista Amazônica de Ensino de Ciências, 9, (2016).

[28] G. Iachel, M. G. Bacha, M. P. de Paula e R. M. F. Scalvi, Revista Brasileira de Ensino de Física, 31, 4 (2009).

[29] M. G. Gohn. Ensaio: avaliacão em políticas públicas em educação, 14, 50 (2006). 